University of Nebraska - Lincoln

DigitalCommons@University of Nebraska - Lincoln

\title{
Use of Energy Consumption during Milling to Fill a Measurement Gap in Hybrid Additive Manufacturing
}

\author{
K. L. M. Avegnon \\ P. Noll \\ M. R. Uddin \\ G. Madireddy \\ R. Williams
}

See next page for additional authors

Follow this and additional works at: https://digitalcommons.unl.edu/mechengfacpub

Part of the Mechanics of Materials Commons, Nanoscience and Nanotechnology Commons, Other Engineering Science and Materials Commons, and the Other Mechanical Engineering Commons

This Article is brought to you for free and open access by the Mechanical \& Materials Engineering, Department of at DigitalCommons@University of Nebraska - Lincoln. It has been accepted for inclusion in Mechanical \& Materials Engineering Faculty Publications by an authorized administrator of DigitalCommons@University of Nebraska Lincoln. 
Authors

K. L. M. Avegnon, P. Noll, M. R. Uddin, G. Madireddy, R. Williams, A. Achuthan, and M. P. Sealy 


\title{
Use of Energy Consumption during Milling to Fill a Measurement Gap in Hybrid Additive Manufacturing
}

\author{
K. L. M. Avegnon, ${ }^{1}$ P. Noll, ${ }^{1}$ M. R. Uddin, ${ }^{1}$ G. Madireddy, ${ }^{1}$ R. E. Williams, ${ }^{1}$
}

\author{
A. Achuthan, ${ }^{2}$ M. P. Sealy ${ }^{1}$
}

1. Department of Mechanical and Materials Engineering, University of Nebraska-Lincoln, Lincoln, Nebraska, USA

2. Department of Mechanical and Aeronautical Engineering, Clarkson University, Potsdam, New York, USA

Corresponding author - M. P. Sealy, email sealy@unl.edu

\begin{abstract}
Coupling additive manufacturing (AM) with interlayer peening introduces bulk anisotropic properties within a build across several centimeters. Current methods to map high resolution anisotropy and heterogeneity are either destructive or have a limited penetration depth using a nondestructive method. An alternative pseudo-nondestructive method to map high-resolution anisotropy and heterogeneity is through energy consumption during milling. Previous research has shown energy consumption during milling correlates with surface integrity. Since surface milling of additively manufactured parts is often required for post-processing to improve dimensional accuracy, an opportunity is available to use surface milling as an alternative method to measure mechanical properties and build quality. The variation of energy consumption during the machining of additive parts, as well as hybrid AM parts, is poorly understood. In this study, the use of net cutting specific energy was proposed as a suitable metric for measuring mechanical properties after interlayer ultrasonic peening of 316 stainless steel. Energy consumption was mapped throughout half of a cuboidal build volume. Results indicated the variation of net cutting specific energy increased farther away from the surface and was higher for hybrid AM compared to as-printed and wrought. The average lateral and layer variation of the net cutting specific energy for printed samples was $81 \%$ higher than the control, which indicated a significantly higher degree of heterogeneity. Further, it was found that energy
\end{abstract}


consumption was an effective process signature exhibiting strong correlations with microhardness. Anisotropy based on residual strains were measured using net cutting specific energy and validated by hole drilling. The proposed technique contributes to filling part of the measure gap in hybrid additive manufacturing and capitalizes on the preexisting need for machining of AM parts to achieve both goals of surface finish and quality assessment in one milling operation.

Keywords: hybrid additive manufacturing, milling, energy, glocal integrity, ultrasonic peening

\section{Introduction}

Hybrid additive manufacturing (AM) processes are defined as the use of AM with one or more secondary processes or energy sources that are fully coupled and synergistically affect part quality, functionality, and/ or process performance [1]. Coupling additive manufacturing (AM) with surface treatments improves mechanical properties and performance of printed parts by forming a complex glocal integrity that affects plastic flow [2]. Glocal integrity refers to a cumulative surface integrity caused by applying surface treatments to multiple layers during AM. This interlayer processing introduces highly heterogeneous and anisotropic properties across a build that comprises a complex glocal integrity. Mapping the heterogeneity of these properties is challenging using existing methods due to a lack of resolution or accuracy. Techniques such as X-ray diffraction or hole drilling are accurate, but measurement over centimeters in depth are impractical and require material removal, which is destructive. The high cost of metal additive manufacturing limits the ability to print excess parts for destructive evaluation. More practical volumetric approaches to measure residual stress that are nondestructive include synchrotron or neutron diffraction; however, these methods have limited resolution and are accessible only through national labs. An alternative method is needed that enables rapid, high-resolution mapping of material properties that is nondestructive. The proposed method, which is the use of milling machines as measurement tools, would bridge the gap between accessibility and spatial resolution. The measurement gap for residual stress caused by hybrid additive manufacturing is shown in Figure 1. Existing methods fail to capture high spatial resolution across large penetration depths. Similar gaps exist for measuring microhardness and microstructure across hybrid additive manufactured constructs. Although ultrasound is a promising nondestructive approach, understanding the influence of texture and grain morphology on wave speed and backscatter remain critical technical barriers to direct measurement of glocal integrity [3, 4]. A pseudo-nondestructive method to map high-resolution heterogeneity is measuring energy consumption during end-milling of AM parts (Fig. 2). Milling is often used to improve the surface finish after additive manufacturing. The average surface roughness ( $\mathrm{Ra}$ ) obtained after additive manufacturing of 316 stainless steel using powder bed fusion (Matsuura Lumex Avance-25) was $14.05 \mu \mathrm{m}$. Thus, milling is an important sequence in the manufacturing process chain to improve part quality. Further, energy consumption has shown to correlate with surface integrity caused by milling [5]. However, this relationship has not been shown for a preexisting glocal integrity imparted by AM or hybrid AM. The approach capitalizes on the preexisting need for machining as a pseudo-nondestructive technique to measure heterogeneous properties imparted by 
interlayer surface treatments. The advantage of this approach is achieving both goals of surface finish and validation using one milling operation and helps fill the measurement gap in hybrid AM. Incremental interlayer milling extends across five or more decades of penetration depth to capture glocal integrity with a spatial resolution less than $100 \mu \mathrm{m}$ (blue dashed line in Fig. 1).

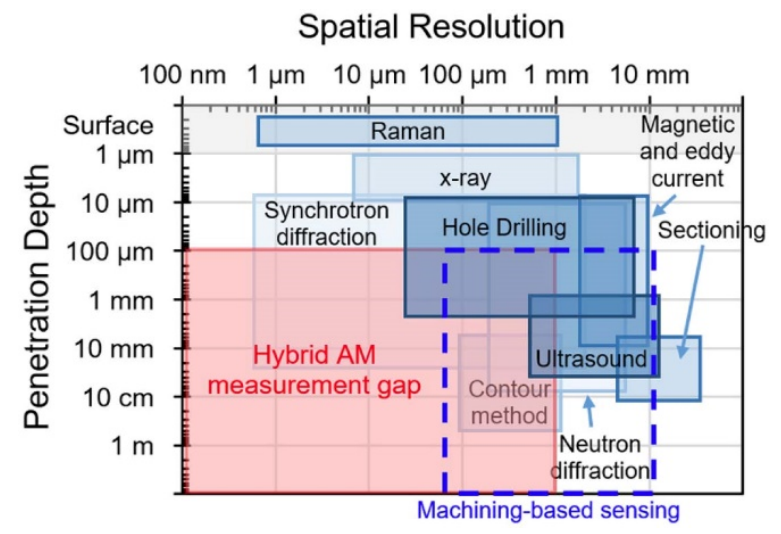

Figure 1. Measurement gap for residual stress in hybrid additive manufacturing (AM). Modified from [6,7].

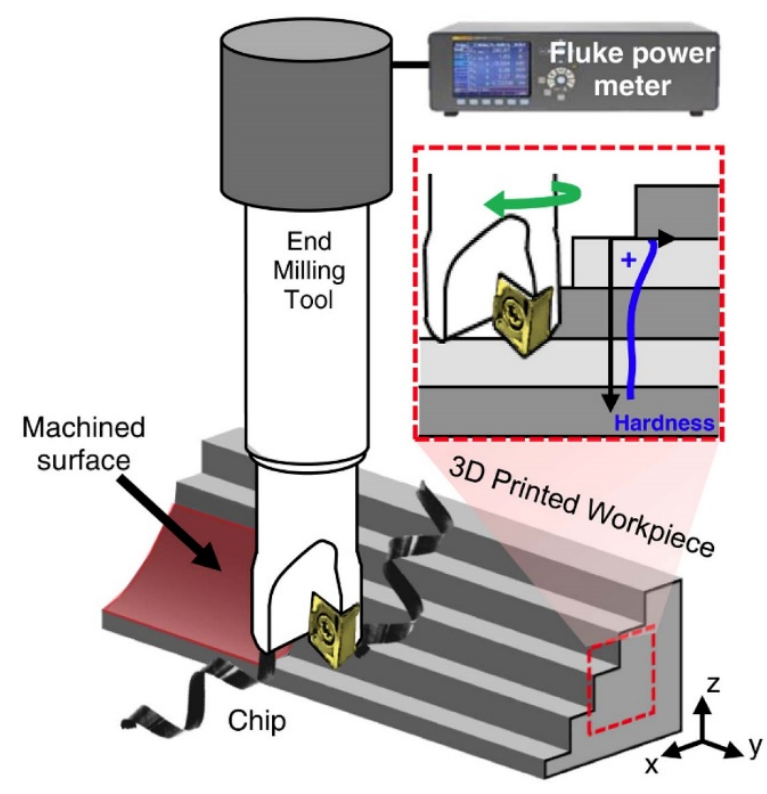

Figure 2. Machining-based sensing (MBS) to measure glocal integrity (e.g., hardness) of $3 \mathrm{D}$ printed parts via energy consumption during the cutting process.

The purpose of this research is to use surface-based machining to validate a unique glocal integrity imparted by interlayer surface treatments. Local regions of internal 
reinforced domains are created by interlayer surface treatments. However, the underlying fundamental relationship between milling-based energy consumption and internally reinforced domains is poorly understood. For example, how does energy consumption vary along the build direction considering the innate variation caused by AM? Further, introducing internally reinforced domains by hybrid-AM further complicates this relationship. Thus, the objective of this study was to map heterogeneous variation of energy consumed during milling of interlayer ultrasonic peened AM samples made from 316 stainless steel. More specifically, the working hypothesis was that anisotropic variation in mechanical properties is proportional to the energy consumed during milling of as-printed and interlayer ultrasonic peened samples. Assuming symmetry, the energy used to machine half of the build volume (rather than surface only) was used to examine the relationship between power consumption and glocal integrity.

\section{Literature review}

\subsection{Hybrid additive manufacturing terminology}

Since hybrid additive manufacturing is an emerging field, this section provides context on hybrid additive manufacturing terminology in order to improve clarity and intent. Further justification for use of this terminology is found in the corresponding references.

\begin{tabular}{ll}
\hline Term & Definition \\
\hline Hybrid additive manufacturing & Broader term used to designate hybrid processes and machines \\
& as well as multi-material, multi-structural, and multifunctional \\
& 3D printing [1] \\
Hybrid additive manufacturing processes & Refers to the use of AM with one or more secondary processes \\
& or energy sources that are fully coupled and synergistically affect \\
part quality, functionality, and/or process performance [1] & In-situ or series combination of an additive manufacturing pro- \\
& cess and secondary energy sources in which physical mechanisms \\
& are fundamentally altered/controlled to affect the resulting \\
& properties of the material and/or part [8]; including "in-situ" \\
& secondary processes and process chains \\
& Inherent or enhanced condition of a surface produced in a \\
& machining or other surface-generating operations [9] \\
& The physical and chemical properties of surfaces layers with \\
& respect to the functional performance of a part [10] \\
& The study and control of the surface layer and the changes that \\
occur during processing that influence the performance of the \\
finished part [11] \\
Refers to the physical and chemical properties of components \\
due to a cumulative surface integrity enabled by secondary pro- \\
cessing of individual layers during additive manufacturing [2]. \\
Glocal is a portmanteau to describe how local changes cause \\
global effects.
\end{tabular}

Continued next page 
Continued from previous page

\begin{tabular}{ll}
\hline Term & Definition \\
\hline Internal reinforced domains & $\begin{array}{l}\text { Temporary accessible regions during AM locally reinforced by } \\
\text { a secondary process with a high degree of freedom regarding } \\
\text { their design [12] }\end{array}$ \\
Refers to anisotropic residual stress/strain fields created by hy- \\
brid AM (e.g., interlayer ultrasonic peening) while assuming an \\
elastically isotropic material; modeled with a constant elastic \\
modulus and Poisson's ratio. \\
Inhomogeneous properties throughout a build volume as meas- \\
ured by residual stress, hardness, microstructure, porosity, con- \\
ductivity, resistance, dislocation density, magnetism, etc.
\end{tabular}

\subsection{Interlayer ultrasonic peening during additive manufacturing}

Hybrid AM by ultrasonic peening (UP) is applying ultrasonic energy to a workpiece layer by layer or multiple layers thereof using an electromechanical transducer. UP is a mechanical surface treatment capable of imparting compressive residual stress, stress relief, and microstructural grain refinement. UP is a low-cost simple solution to improve interlayer mechanical properties relatively quickly. One of the open questions in this field is which layers and where secondary processing should occur. A model was developed to determine hybrid ultrasonic impact treatment conditions based on the thickness of each deposited layer, linear energy density from AM, ultrasonic frequency, and amplitude in the UIT process [13]. However, this model assumes every layer should be secondarily treated rather than identifying the proper solution for a given load or environmental condition. Lu et al. demonstrated directional dependence on strength and ductility of fixed interval laser peening using horizontal and vertical configurations [14]; however, the glocal integrity was not mapped across multiple intervals to understand compounding effects. To confirm the proper solution was achieved by selectively peening critical layers during AM, new measurement tools are needed to validate the glocal integrity. Milling-based energy consumption is proposed as alternative tool to measure glocal integrity. Therefore, this study hypothesizes that energy consumed during milling of UP layers is greater than untreated controls. This is based on the observation that hybrid UP treatment while 3D printing stainless steel revealed that peened layers were harder than as-printed layers [15]. Further, this research analyzes the ability to measure anisotropy in hybrid AM and AM-only samples. The use of interlayer UP during powder bed fusion is expected to reduce anisotropy in the lateral (i.e., horizontal) and build directions. Interlayer forging during wire-arc AM on Ti-6Al-4V reduced anisotropy and improved mechanical properties [16]. Similar observations were reported on interlayer micro-rolling during wire-arc AM of bainite steel [17]. Both studies used wire-arc AM, which had a relatively larger melt pool and slower cooling rate compared to powder bed fusion indicating less anisotropy was expected. 


\subsection{Sensing glocal integrity by measuring energy consumption during milling}

\subsubsection{Hybrid additive-subtractive manufacturing}

Coupling milling with additive manufacturing aims to improve surface finish and ensures dimensional accuracy of printed components. Automation of the process and real time repairs regarding dimensional accuracy remain open challenges [18,19]. Residual stress induced by milling of additive parts causes a new stress equilibrium that further affects part distortion [20]. The implementation of these solutions is time consuming, and there is no efficient way to certify the surface/glocal integrity imparted to the printed parts. The current study focuses on presenting milling as a hybrid process that dual serves as a measurement tool to measure glocal integrity imparted to an additive component subjected to interlayer peening as a second hybrid process.

Milling in situ or out-of-envelope has different effects on the cutting specific energy. Milling in situ reduces machinability, and there is a possibility that the unsintered metallic powders interfere between the flank face and workpiece to create abusive milling conditions. Milling has proven to increase specific cutting energy from $14 \%$ to $35 \%$ [21,22]. To mitigate excessive tool wear and the related increase in energy, milling was conducted outof-envelop on a 3-axis milling machine (Optomec LENS Hybrid Machine Tool Series).

\subsubsection{Energy consumption as a process signature}

Every manufacturing process produces a unique measurable process signature. The process signature is useful for predicting suitable machining processes to achieve functional properties [23]. In this study, the process signature of the machining process is an energybased approach to map the glocal integrity of the workpiece. Monitoring energy consumption during milling is an effective tool to establish coherence between functional properties and energy consumption [5]. However, during milling, properties like residual stress and microstructure are altered at the milled surface and subsurface, whereas hardness does not reveal any significant change from milling [24-26]. Hence, the specific approach in this preliminary study was to machine a volume of material and to correlate the microhardness and residual stress with the electrical energy consumption during milling.

\subsubsection{Metrics for process signature}

The most widely reported metric for specific energy is at the machine level, which includes total energy consumed divided by the material removal rate (i.e., total specific energy, $U_{t}$ ) [27]. Modern milling machines include a wide variety of functions, including electric control system, cooling systems, and auxiliary systems. These various functions account for the overwhelming majority of the total energy requirements of the machine tool. The actual machining energy is only $14.8 \%$ of the total specific energy [28]. While total specific energy is best for investigating overall energy efficiency and sustainability [29], it is a poor metric for correlating with mechanical properties and not valid for predicting energy consumed at the individual process level. To remove the influence of peripheral loads that dilute the energy signal, the concept of net cutting specific energy was established to characterize energy consumed by the actual cutting process. The net cutting specific energy $\left(U_{n c}\right)$ was defined as the difference in total power and air-cutting power per unit material volume 
removed. This approach to quantify a process signature is unique to conventional machining centers. Conventional milling machines resort to the spindle motor resistance as a feedback loop system that adjusts the electrical energy required based on the cutting conditions and material properties. Thus, measuring electrical energy needed by the spindle motor is a direct measure of the work needed to shear the workpiece. Hybrid additive manufacturing systems that couple AM and milling offer inherent capabilities to map glocal integrity using energy-based milling as a sensor. Milling has shown not to negatively affect surface integrity or mechanical properties in hybrid systems [30].

\section{Materials and methods}

In this study, 316 stainless steel samples were printed using powder bed fusion on a Matsuura Lumex Avance-25 and coupled with interlayer ultrasonic peening. The powder was Matsuura Stainless 316L (SUS316L JIS equivalent) with an average powder size of $29 \pm 10 \mu \mathrm{m}$ (Fig. 3). The layer thickness, laser power, and scanning speed were $50 \mu \mathrm{m}, 320 \mathrm{~W}$, and $700 \mathrm{~mm} / \mathrm{s}$, respectively. The raster orientation was randomized using $\pm 45^{\circ}$ within $5 \mathrm{~mm} \times 5 \mathrm{~mm}$ cells that were printed randomly. All samples were cuboid coupons of size (L) $25.4 \mathrm{~mm} \times(\mathrm{W}) 25.4 \mathrm{~mm} \times(\mathrm{H}) 10 \mathrm{~mm}$. Wrought and as-printed samples provided baseline controls. The as-printed sample was continuously printed, and wrought samples were annealed 316 stainless steel (ASTM A240, Rockwell B95) with a yield strength of $207 \mathrm{MPa}$. Samples were ground using $\mathrm{SiC}$ papers with 400,600 , and 800 grit followed by polishing with $3 \mu \mathrm{m}$ diamond suspensions and $0.05 \mu \mathrm{m}$ alumina oxide powder. Next, samples were electrolytically etched in a $10 \%$ oxalic acid solution applying a potential difference of $5 \mathrm{~V}$ for $60 \mathrm{~s}$ to reveal the melt pool.

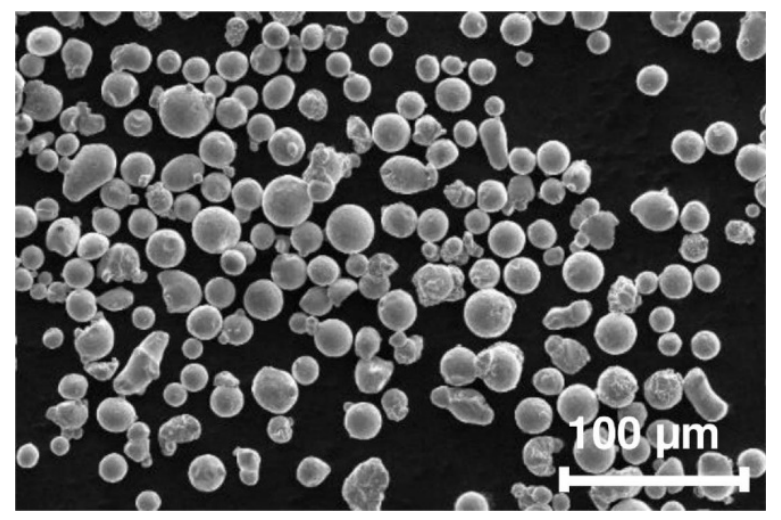

Figure 3. Powder morphology of Matsuura stainless steel 316L powder.

\subsection{Asynchronous ultrasonic peening procedure}

Hybrid samples were asynchronously printed and ultrasonic peened out of envelope every 10 layers (i.e., $500 \mu \mathrm{m}$ ). The ultrasonic peening frequency was $20 \mathrm{kHz}$ with a power output of $100 \mathrm{~W}$. The peening head used 4 needles that were $3 \mathrm{~mm}$ in diameter with a $2 \mathrm{~mm}$ 
spacing. Each surface was peened once (i.e., 100\% coverage) with an oscillatory raster pattern shown in Figure 4.

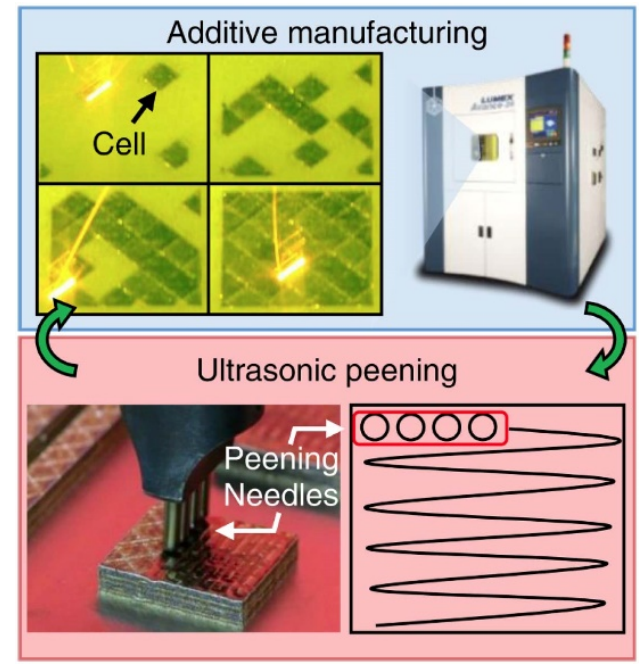

Figure 4. Hybrid-AM coupling powder bed fusion with ultrasonic peening.

\subsection{Energy consumption analysis}

Milling was performed on an Optomec LENS Hybrid Machine Tool Series 500 (originally a Fryer Compact Milling Series CM-20) using two TiN/TiAIN coated carbide inserts (ENHU 050304R-pH on an Ingersoll DiPos-Tetra series 90 end mill cutter (1TJ1C-05012S4R0). The cutting tool diameter was $12.7 \mathrm{~mm}$. The total current and voltage consumed during milling was measured using a Fluke Norma 5000 power analyzer. The sampling frequency was $341 \mathrm{kHz}$, and the average time was $150 \mathrm{~ms}$. This results in approximately 44 data points along a cutting length $(L)$ of $25.4 \mathrm{~mm}$ at a feed rate $\left(v_{f}\right)$ of $251 \mathrm{~mm} / \mathrm{min}$. The lateral variation of the net cutting specific energy for the wrought sample $\left(11.5 \pm 0.6 \mathrm{~J} / \mathrm{mm}^{3}\right)$ suggests that the 44 data points was enough to quantify the average specific energy of every milling pass. The milling parameters are given in Table 1. Samples were assumed symmetric with respect to the raster direction. Thus, half of each sample was milled while the other half was used for materials characterization. The axial depth of cut was equivalent to one peening cycle (i.e., L10 or ten PBF layers) as shown in Figure 5. Machining increments were offset from peened layers by $0.25 \mathrm{~mm}$ such that milling occurred between two peened layers.

\begin{tabular}{ll}
\hline Table 1. Milling parameters & \\
\hline Cutting process parameters & \multicolumn{1}{c}{ Value } \\
\hline Axial depth of cut $\left(a_{p}\right)$ & $0.5 \mathrm{~mm}$ \\
Radial depth of cut $\left(a_{e}\right)$ & $0.5 \mathrm{~mm}$ \\
Cutting speed $(v)$ & $100 \mathrm{~m} / \mathrm{min}$ \\
Feed per tooth $(f)$ & $0.05 \mathrm{~mm} /$ tooth \\
Material removal rate $(M R R)$ & $1.04 \mathrm{~mm}^{3} / \mathrm{s}$ \\
Milling mode & Down milling \\
\hline
\end{tabular}




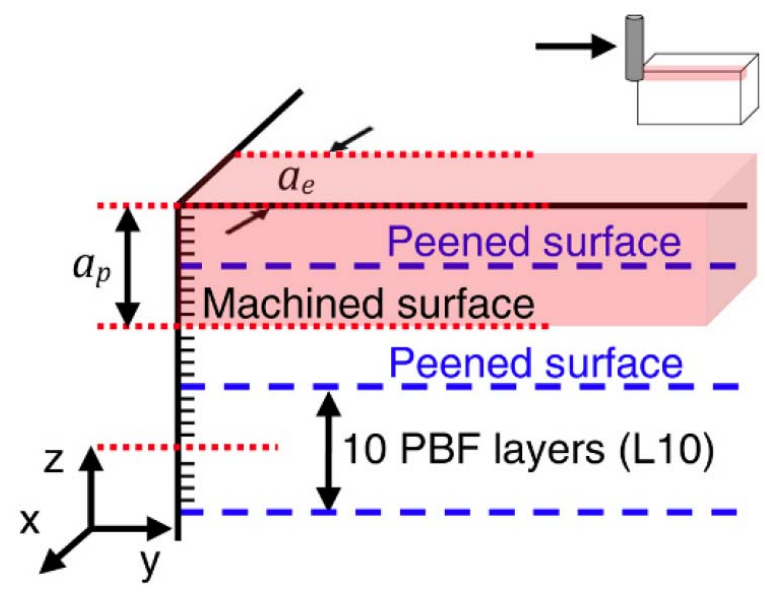

Figure 5. Peening and machining diagram.

The energy was quantified in terms of total $\left(U_{t}\right)$ and net cutting specific energy $\left(U_{n c}\right)$ in units of $\mathrm{J} / \mathrm{mm}^{3}$. The total specific energy was defined as the total power consumed $\left(P_{t}\right)$ divided by the material removal rate $(M R R)$. The net cutting specific energy $\left(U_{n c}\right)$ was calculated from the net cutting power $\left(P_{n c}\right)$ divided by the material removal rate [30]. According to the cutting tool manufacturer, the maximum allowable depth of cut and usable length was $4.6 \mathrm{~mm}$ and $19.1 \mathrm{~mm}$, respectively. However, a stair-step cutting plan (Fig. 6a) was used to minimize the excessive tool wear of the cutting inserts (Fig. 6b). The measured flank wear in Figure $6 \mathrm{~b}$ is approximately $0.4 \mathrm{~mm}$. A 3D view of the tool showed excessive crater wear and a complete destruction of the tool's nose. Since more tool wear results in more inaccurate energy data [31], the maximum engagement between the sidewall and flank face was approximately $2.5 \mathrm{~mm}$ (or less) on the last cut of each layer. Also, tool wear was the dominant factor in energy consumed during cutting at the process level rather than the primary cutting conditions, such as speed or depth of cut [32]. Further, the stairstep approach minimized redundant work caused by friction between the flank face and workpiece. Excessive redundant work would dilute the energy data leading to inaccurate correlations with glocal integrity. 


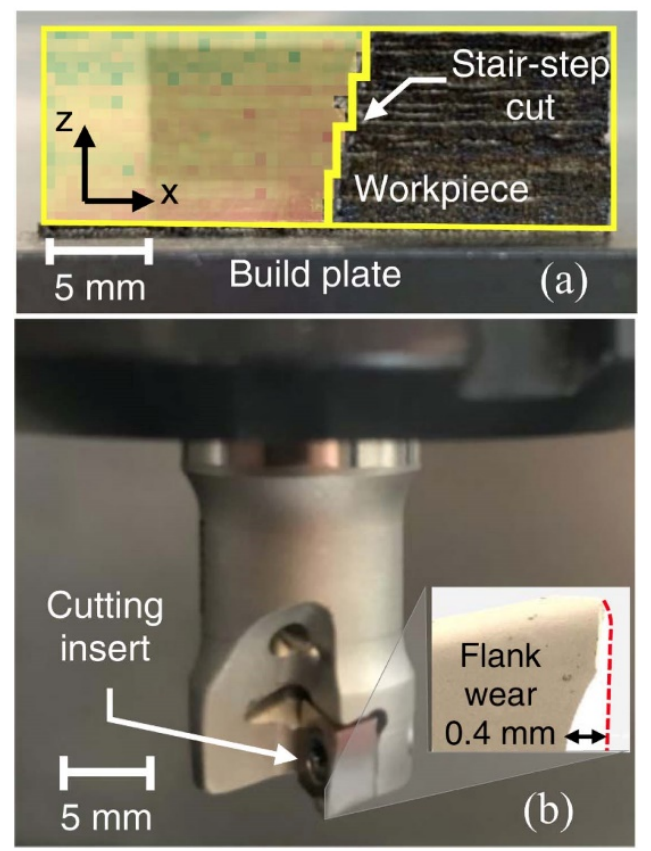

Figure 6. (a) Reduced number of lateral passes along the depth (i.e., stair-steps) to minimize abrasion between tool and workpiece and (b) excessive tool wear on the flank face without using a stair-step approach.

Tool wear rate was measured after five milling cycles (i.e., approximately $16.6 \mathrm{~min}$ of cutting) for each treatment condition. After $50 \mathrm{~min}$, tool wear was check more routinely by measuring after each machining cycle. SEM images of the tool's condition were taken using a JEOL JCM-6000PLUS benchtop SEM.

\section{Results and discussion}

\subsection{Tool wear}

The evolution of flank wear throughout milling is shown in Figure 7. The inserts used to mill printed samples, i.e., as-printed and hybrid, exhibited a faster wear rate compared to wrought milling inserts. The maximum flank wear after $65 \mathrm{~min}$ was $0.10 \mathrm{~mm}, 0.07 \mathrm{~mm}$, and $0.06 \mathrm{~mm}$ for hybrid, as-printed, and wrought samples, respectively. The tool break-in region was similar for both printed conditions. All inserts appeared to be in the stable tool wear growth region after 65 min of milling. Between 20 and $65 \mathrm{~min}$, the wear rate for hybrid cutting inserts was fastest. Flank wear for hybrid cutting inserts was approximately $32-38 \%$ higher than as-printed and wrought samples, respectively. One mechanism driving this observation was that work hardening induced by ultrasonic peening increased the strength and hardness. As a result, inserts used in cutting hybrid samples were exposed to higher cutting forces that ultimately shortened tool life. Based on this observation, the cutting energy required for hybrid samples was expected to be higher compared to the control samples. 


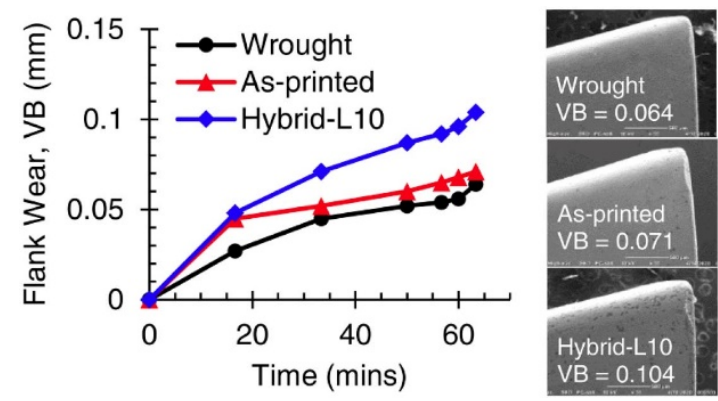

Figure 7. Tool wear curve from end milling hybrid, as-printed, and wrought 316L stainless steel.

\subsection{Energy consumption results}

The power consumed during milling was measured across 3 phases supplying power to the machine tool. Representative power curves are shown in Figure 8 where the wrought net cutting power refers to the difference in power consumption while milling the wrought sample to air cutting. The wrought total cutting power refers to the average total power consumed while milling the wrought sample. The measured total power includes several peripheral systems (e.g., chillers, pumps) that cycle on and off independently of printing or machining. Therefore, the air cutting and cutting powers may be different (i.e., shifted); however, the net cutting specific energy that captures the difference between cutting and air cutting was unaffected and did not influence the quality of the measurements. The power consumed on each lateral increment was quantified in terms of total specific energy $\left(U_{t}\right)$ and net cutting specific energy $\left(U_{n c}\right)$. The specific energy of each sample was mapped across the $x-z$ plane as shown in Figure 9, where each square corresponds to the specific energy for one lateral increment (i.e., one power curve divided by the MRR). The green color depicts the minimum energy consumed, and the red color depicts the maximum energy consumed. The objective was to examine the variation of energy consumption across the lateral (x) direction and the build (z) direction for as-printed and hybrid UP samples.

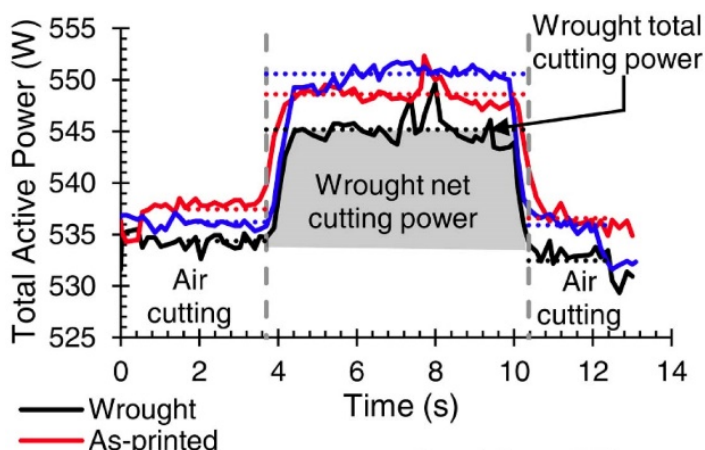

Avg Time: $150 \mathrm{~ms}$

Figure 8. Representative total active power curves for wrought, as-printed, and hybrid samples. 

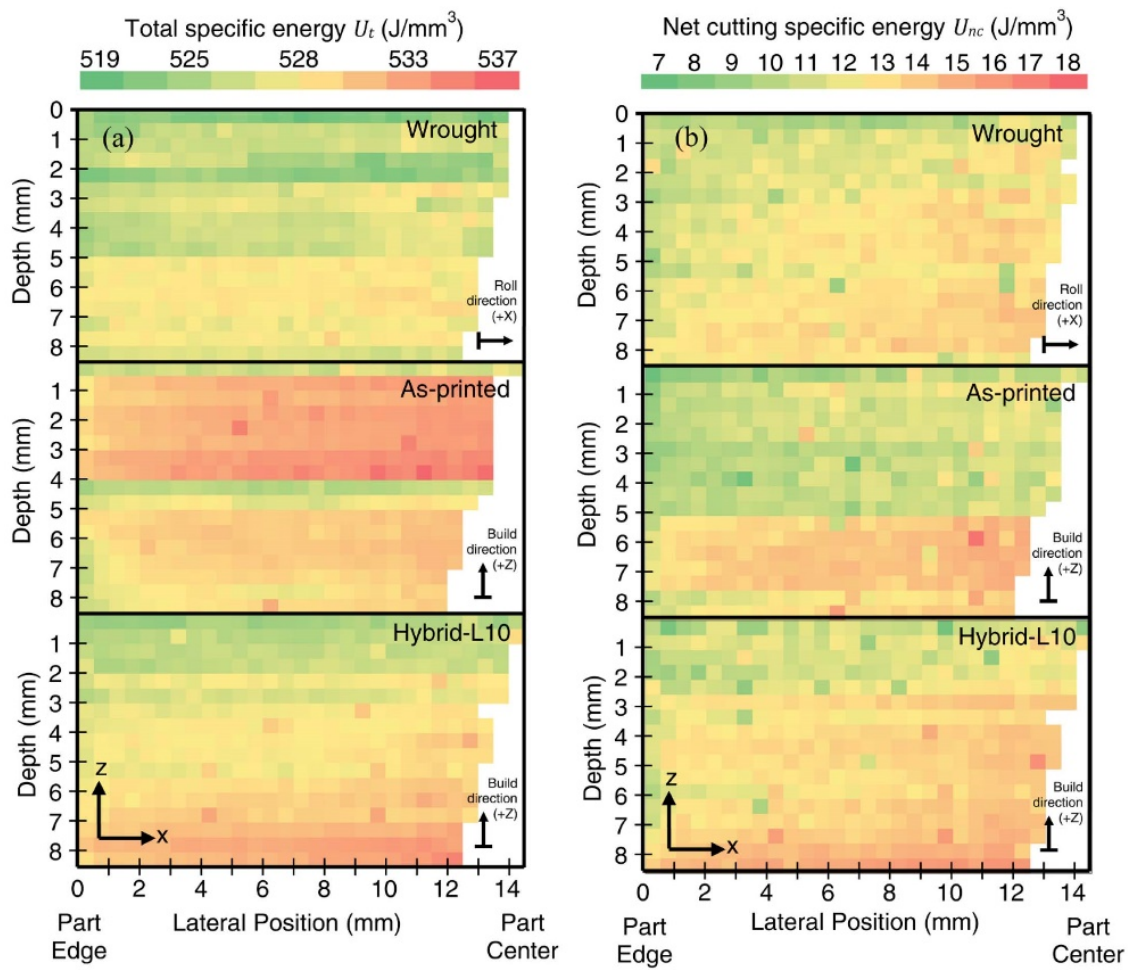

Figure 9. Energy maps for (a) total specific energy, $U_{t}$ and (b) net cutting specific energy, $U_{n c}$.

The average specific energy and standard deviation is provided in Table 2. As expected, the total and net cutting specific energy profiles for the wrought sample was relatively uniform as evidenced by the lowest degree of variation. Printed samples varied more from layer to layer and were generally more uniform within the same layer. As expected, the wrought sample varied less in both $\mathrm{x}$ - and $\mathrm{z}$-directions as compared to the printed samples. This observation indicates that the hot rolled and annealed sample was relatively more homogeneous. Interestingly, the total and net cutting specific energy profiles for the printed samples exhibited different trends. The as-printed condition exhibited the highest total specific energy but the lowest net cutting specific energy. The net cutting specific energy for the hybrid sample was approximately $8.3 \%$ higher than wrought and as-printed. The hybrid sample was expected to be higher since cold working intermittent layers requires more energy to shear. This assumes harder and tougher materials require more energy to cut. This observation further supports the argument that net cutting specific energy is a better indicator for glocal integrity since total specific energy dilutes information. 
Table 2. Average total and net cutting specific energy and variation

\begin{tabular}{|c|c|c|c|c|c|c|}
\hline & \multicolumn{3}{|c|}{ Total specific energy $\left(U_{t}\right)$} & \multicolumn{3}{|c|}{ Net cutting specific energy $\left(U_{n c}\right)$} \\
\hline & Wrought & As-printed & Hybrid & Wrought & As-printed & Hybrid \\
\hline Sample average $\left(\mathrm{J} / \mathrm{mm}^{3}\right)$ & 524.8 & 529.1 & 526.8 & 11.5 & 11.4 & 12.4 \\
\hline Total std. dev. & 2.0 & 3.1 & 2.7 & 1.1 & 1.9 & 1.8 \\
\hline Std. dev. of lateral avg. & 0.4 & 1.3 & 0.9 & 0.6 & 0.7 & 0.8 \\
\hline Std. dev. of layer avg. & 1.8 & 2.8 & 2.7 & 0.7 & 1.7 & 1.5 \\
\hline
\end{tabular}

The average net cutting specific energy as a function of depth and lateral distance from the edge are plotted in Figure 10. Generally, the specific energy increased farther away from the top and sidewall surfaces with one noticeable exception. For total specific energy, the as-printed sample consumed more energy on the first $4.5 \mathrm{~mm}$ along the depth before decreasing. The stair-step approach reduced the amount of data in the center in order to minimize friction between the tool and workpiece that would affect energy consumption data. Based on standard deviations, printed samples were approximately $81 \%$ more heterogeneous compared to the wrought sample. The bulk anisotropy was expected to be higher because of cumulative residual stress and complex microstructure formation driven by the thermal history. Further, the net cutting specific energy varied approximately $86 \%$ more along the build (z-) direction as compared to the lateral (x-) direction indicating a higher degree of bulk anisotropy. The hybrid sample was slightly more homogeneous, indicating that peening every tenth layer reduced natural variation caused by AM.

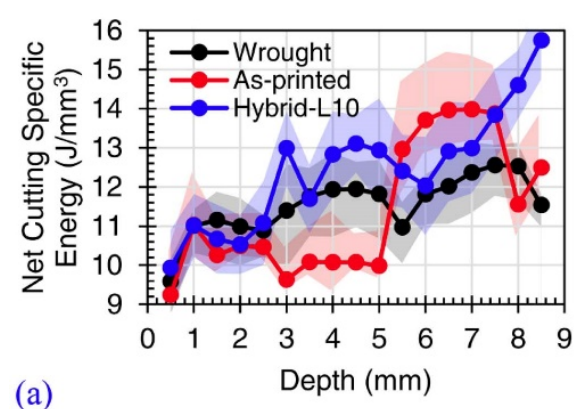

(a)

Figure 10. Average net cutting specific energy as a function of (a) depth and (b) lateral distance from the edge.

\subsection{Glocal integrity in relation to energy consumption}

\subsubsection{Melt pool and microstructure}

The electropolishing procedure revealed melt pool boundaries and various microstructures of the printed samples (Fig. 11). The enclosed area during milling spanned the depth and width of approximately seven and five melt pools, respectively. The layer thickness was $50 \mu \mathrm{m}$. The microstructure of as-printed and hybrid samples were similar and dominated by columnar coarse grains oriented along the build direction that often crossed several melt pools. Inside these coarser grains were finer cellular subgrain structures oriented 
along multiple directions within the same coarse grain. The direction of the heat flux and temperature gradients during melting and remelting resulted in multidirection cooling that gave rise to the random orientation of the subgrain structures. Since milling crossed several melt pools composed of even more coarse grains, any microstructural modifications were thought to have a negligible effect on the cutting energy.

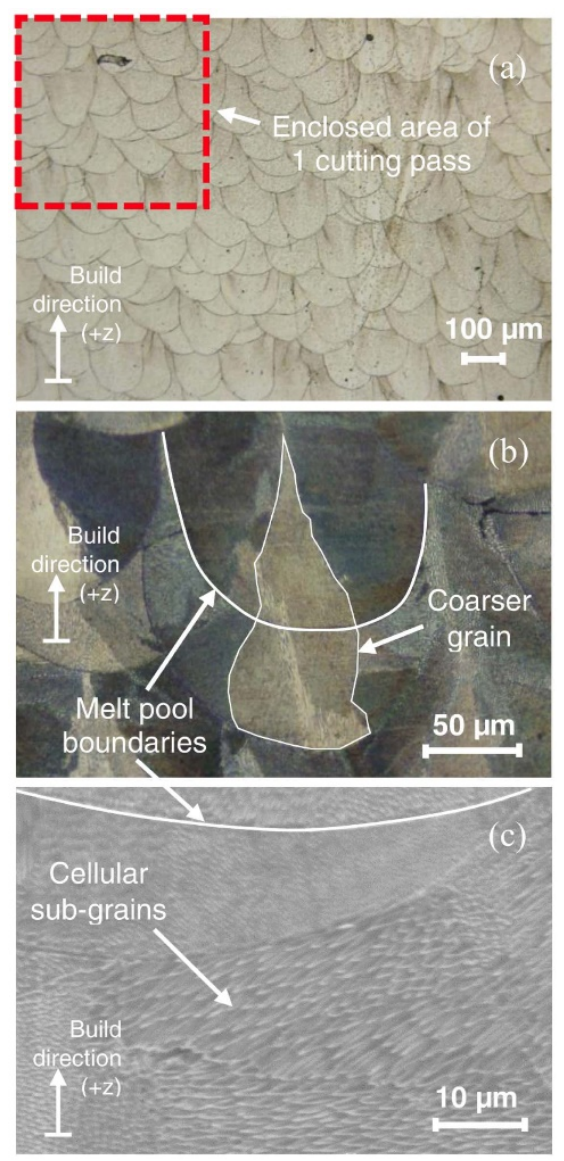

Figure 11. (a) Melt pools from 3D printing 316SS on a Matsuura Lumex Avance-25 with a $50 \mu \mathrm{m}$ layer thickness, (b) coarse grains crossing melt pool boundaries, and (c) cellular subgrains with different orientations.

\subsubsection{Microhardness}

Vickers' microhardness was mapped along the build direction using a LECO LM110 with a force equivalent of $1 \mathrm{~kg}$ and a dwell time of $10 \mathrm{~s}$ (Fig. 12). Each measurement was repeated five times on the xy-plane (on top) of each layer between milling cycles and on the sidewalls before any milling. Due to physical size constraints of the sample and equipment, hardness was mapped only $6 \mathrm{~mm}$ along the build direction from the top printed surface. 

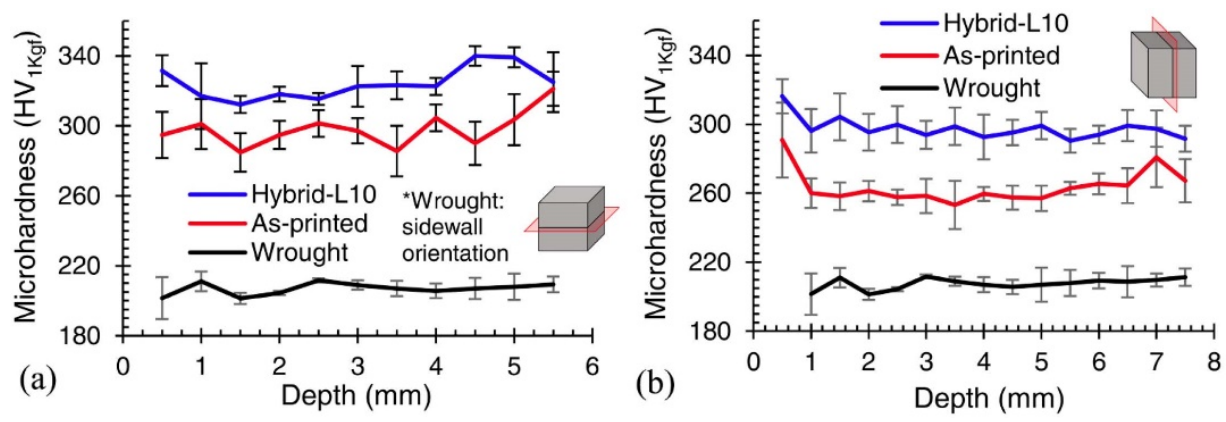

Figure 12. Vickers microhardness of 316 stainless steel measured on (a) xy-plane during milling and (b) sidewall before milling.

Hardness of the hybrid-L10 sample was on average higher than the as-printed sample. The improvement in hardness of the hybrid sample was due to the work hardening printed layers during ultrasonic peening. Since data was collected on the milled surface, it is important to note that the cutting process influenced the measurements and resulted in a higher in-plane hardness compared to the sidewall data. The points of inflection on the xyplane microhardness (Fig. 12a) and net cutting specific energy (Fig. 10a) aligned well between 1 and $6 \mathrm{~mm}$. Results before $1 \mathrm{~mm}$ likely experienced edge effects and after $6 \mathrm{~mm}$ were not measurable due to sample size constraints. For example, the hardness and net cutting specific energy of the as-printed sample both increased $5 \mathrm{~mm}$ below the surface. When the hardness of the hybrid sample was increasing/decreasing, the net cutting specific energy also increased/decreased, accordingly. On the contrary, the total specific energy showed no observable correlation with either in-plane or sidewall microhardness. Since the total energy of the machine tool encompasses energy consumed by other accessories during milling, the power data is diluted, and total specific cutting energy is not representative of glocal integrity.

Results provide growing evidence that net cutting specific energy is a useful metric for correlating with glocal integrity, namely microhardness (Fig. 13). One mechanism driving this observation is that interlayer peening resulted in work hardening that was measurable by both micro-indentation and energy consumed during milling or work hardened layers. Although more experiments are needed, the R-squared values suggest that more than half the variation in microhardness was attributed to the net cutting specific energy. Future studies are needed to examine the influence of other glocal integrity measures, such as residual stress and porosity. 


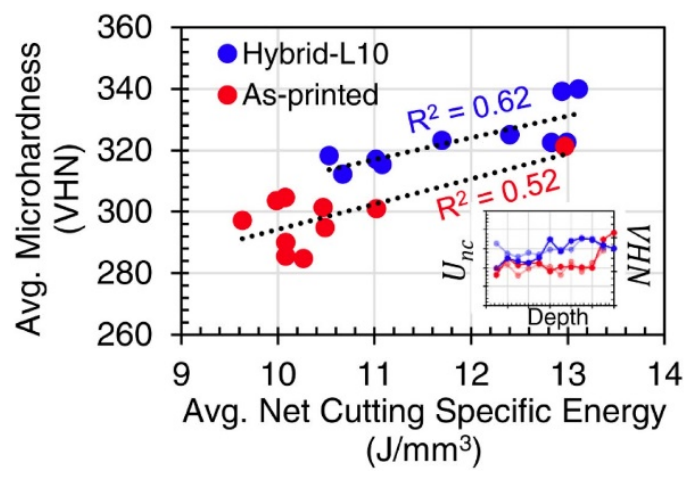

Figure 13. Correlation between microhardness and net cutting specific energy.

\subsubsection{Residual stress and strain}

Residual stress and strain was measured using the hole drilling method according to ASTM E837. The hole-drilling setup was powered by an air compressor which rotates the turbine at 400,000 RPM to drill through an HBM strain gage (1-RY6-1.5/120K) attached to the sample. Residual strains were measured up to a depth of $1 \mathrm{~mm}$ in increments of $16 \mu \mathrm{m}$. The strain data was analyzed using the SINT Eval 7 software to convert the measured strains to residual stresses as appropriate. The correlation between the residual stresses (RS) and the net cutting specific energy $\left(U_{n c}\right)$ is plotted in Figure 14.

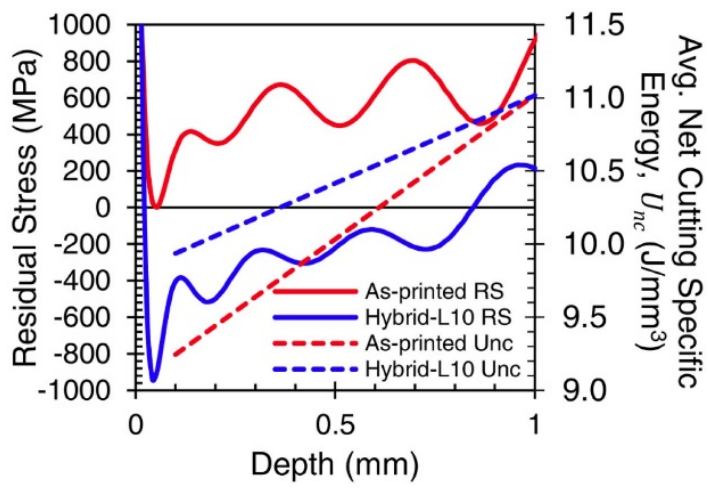

Figure 14. Correlation between residual stress and net cutting specific energy.

The as-printed sample contained predominantly tensile residual stresses as expected. Interlayer ultrasonic peening caused the hybrid sample to shift to predominately compressive residual stresses. Results showed that the net cutting specific energy $\left(U_{n c}\right)$ in the first millimeter was higher for the hybrid sample because more energy was required to machine through compressive residual stress. This observation contradicted the total specific energy $\left(U_{t}\right)$, which consumed more energy while milling the first millimeter of the as-printed sample. Results further support the fact that total energy consumed is an inaccurate measure of glocal integrity, and analysis of the net cutting specific energy is needed to map internally reinforced regional domains. 
To evaluate if $U_{n c}$ was capable of capturing lateral anisotropy frequently observed in the residual strain measurements of hybrid samples, the $\mathrm{x}$ - and $\mathrm{y}$-direction strains along the depth and the corresponding directional specific energies are shown in Figure 15. Residual strains were directly analyzed from the strain gages to minimize further processing and filtering of the data based on ASTM E837 for hole drilling. The results highlight the ability of net cutting specific energy to capture anisotropy in hybrid additive manufacturing.
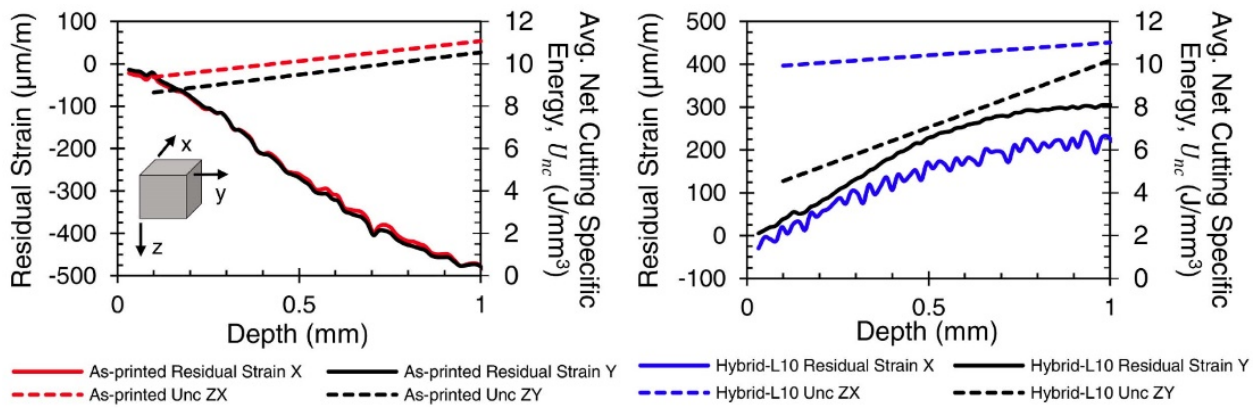

Figure 15. Use of residual strain and net cutting specific energy $\left(U_{n c}\right)$ to measure anisotropy in additive manufactured 316 stainless steel: (a) as-printed and (b) hybrid-L10.

The negative residual strains in the as-printed sample (indicating tensile residual stress) did not vary in the $x$ - and y-directions. Similarly, the difference between directions for $U_{n c}$ in Figure 15a was approximately $6 \%$, which indicated minimal or negligible anisotropy that was likely attributed to alternating print raster patterns. In the hybrid sample (Fig. $15 \mathrm{~b})$, the degree of anisotropy was considerably higher. $U_{n c}$ captured a 30\% difference between the lateral $x$ - and y-directions. Residual strain measurements for hybrid AM provide support that the peening procedure introduce a higher degree of anisotropy compared to printing alone and that it is measurable by monitoring energy consumption.

\section{Summary and conclusions}

The objective of this study was to map anisotropic and heterogeneous variation of energy consumed during milling of interlayer ultrasonic peened AM samples made from 316 stainless steel. Hybrid cuboids were printed by powder bed fusion, ultrasonically peened out of envelope, and compared with as-printed and wrought control samples. The total and net cutting specific energy were mapped along the xz-plane to understand natural variation from the print process and induced variation caused by cold working discrete layers. The influence of interlayer peening on flank wear was assessed. The microhardness, microstructure, and residual stress were also measured to determine if there were observable correlations with total and net cutting specific energy. The key results are summarized as follows:

- For the first time, net cutting specific energy was shown to capture glocal integrity variation induced by hybrid additive manufacturing. 
- Machining after ultrasonic peening every 10 layers accelerated tool wear approximately $35 \%$ over as-printed and wrought samples due to cold working. Microhardness was higher on hybrid samples and more closely correlated with net cutting specific energy rather than total specific energy. Although this seems obvious, this is significant because [2] highlights that interlayer laser peening decreased hardness compared to an as-printed control sample, which contradicts conventional thinking that cold working discrete layers increases hardness that would in turn shorten tool life. The hardness reported in [2] and remeasured using ultrasound in [3] suggest that residual stress relaxation during indentation caused the hardness to artificially measure lower. In this work, cutting energy was an independent measure to confirm increased hardness after interlayer cold working.

- The degree of variation in net cutting specific energy between layers was $86 \%$ higher on average compared to the lateral variation (along the cutting direction), which indicates a high degree of bulk anisotropy in the $x-z$ plane.

- The average lateral and layer variation for additive manufactured samples (both as-printed and hybrid) was $81 \%$ higher than wrought based on net cutting specific energy, which indicated a significantly higher degree of heterogeneity.

- Total and net cutting specific energy generally increased away from the surfaces.

- Anisotropic residual strain fields induced by ultrasonic peened were measured by net cutting specific energy and validated by hole drilling (ASTM E837).

- The hybrid sample was approximately $14 \%$ and $12 \%$ more homogeneous in the lateral x-direction and layer z-direction, respectively, as measured by a lower standard deviation, indicating that peening every tenth layer reduced natural variation caused by AM.

- As expected, total specific energy produced more noise and weaker correlations with glocal integrity.

In conclusion, the proposed concept to use milling to measure anisotropy and heterogeneity caused by interlayer ultrasonic peening is feasible. The proposed technique contributes to filling part of the measure gap in hybrid additive manufacturing by increasing the spatial resolution to 10s or 100s of microns across large penetration depths exceeding several centimeters. The preexisting need for machining of AM parts is advantageous for industry in achieving both goals of surface finish and quality assessment in one milling operation across larger build volumes.

Declaration of Competing Interest - The authors declare the following financial interests/personal relationships which may be considered as potential competing interests: Michael P. Sealy reports equipment, drugs, or supplies was provided by National Science Foundation. Michael P. Sealy reports financial support was provided by National Science Foundation.

Acknowledgments - Resources and support for this research were provided by NSF CMMI: 1846478, the Nebraska Engineering Additive Technologies (NEAT) Lab, and the Mechanical and Materials Engineering Department (Dr. Jeffrey Shield) at the University of Nebraska-Lincoln as part of 
an undergraduate/graduate investigative research course in additive manufacturing. The research was performed in part in the Nebraska Nanoscale Facility: National Nanotechnology Coordinated Infrastructure and the Nebraska Center for Materials and Nanoscience, which are supported by the National Science Foundation under Award ECCS: 1542182, and the Nebraska Research Initiative.

\section{References}

[1] M.P. Sealy, G. Madireddy, R.E. Williams, P. Rao, M. Toursangsaraki, Hybrid processes in additive manufacturing, ASME J. Manuf. Sci. Eng. 140 (6) (2018), 060801, https://doi.org/10.1115/ 1.4038644 .

[2] M.P. Sealy, H. Hadidi, C.J. Kanger, X.L. Yan, B. Cui, J.A. McGeough, Glocal integrity in 420 stainless steel by asynchronous laser processing, CIRP Ann. 68 (1) (2019) 189-192, https://doi.org/ 10.1016/j.cirp.2019.04.105.

[3] M.P. Sealy, H. Hadidi, L.D. Sotelo, W.L. Li, J.A. Turner, J.A. McGeough, Compressive behavior of 420 stainless steel after asynchronous laser processing, CIRP Ann. 69 (1) (2020) 169-172, https://doi.org/10.1016/j.cirp.2020.04.059.

[4] L.D. Sotelo, H. Hadidi, C.S. Pratt, M.P. Sealy, J.A. Turner, Ultrasonic mapping of hybrid additively manufactured 420 stainless steel, Ultrasonics 110 (2021), 106269, https://doi.org/10.1016/ j.ultras.2020.106269.

[5] M.P. Sealy, Z.Y. Liu, Y.B. Guo, Z.Q. Liu, Energy based process signature for surface integrity in hard milling, J. Mater. Process. Technol. 238 (2016) 284-289, https://doi.org/10.1016/j.jmatprotec .2016.07.038.

[6] P.J. Withers, M. Turski, L. Edwards, P.J. Bouchard, D.J. Buttle, Recent advances in residual stress measurement, Int. J. Press. Vessels Pip. 85 (3) (2008) 118-127, https://doi.org/10.1016/j.ijpvp .2007.10.007.

[7] G.S. Schajer, Practical Residual Stress Measurement Methods, John Wiley \& Sons, West Sussex, United Kingdom, 2013.

[8] S. Webster, H. Lin, F.M. Carter III, K. Ehmann, J. Cao, Physical mechanisms in hybrid additive manufacturing: a process design framework, J. Mater. Process. Technol. 291 (2021), 117048, https://doi.org/10.1016/j.jmatprotec.2021.117048.

[9] B. Breidenstein, Surface integrity, the international academy for production engineering, in: L. Laperrière, G. Reinhart (Eds.), CIRP Encyclopedia of Production Engineering, Springer, Berlin, Heidelberg, 2014, https://doi.org/10.1007/978-3-642-20617-7_6600.

[10] M. Field, J.F. Kahles, J.T. Cammett, A review of measuring methods for surface integrity, CIRP Ann. 21 (2) (1972) 219-238.

[11] M.P. Groover. Fundamentals of Modern Manufacturing: Materials, Processes, and Systems, seventh ed, John Wiley \& Sons, United Kingdom, 2020.

[12] D. Meyer, N. Wielki, Internal reinforced domains by intermediate deep rolling in additive manufacturing, CIRP Ann. 68 (1) (2019) 579-582, https://doi.org/10.1016/j.cirp.2019.04.012.

[13] C. Zhou, F. Jiang, D. Xu, C. Guo, C. Zhao, Z. Wang, J. Wang, A calculation model to predict the impact stress field and depth of plastic deformation zone of additive manufactured parts in the process of ultrasonic impact treatment, J. Mater. Process. Technol. 280 (2020), 116599, https://doi.org/ 10.1016/j.jmatprotec.2020.116599.

[14] J. Lu, H. Lu, X. Xu, J. Yao, J. Cai, K. Luo, High-performance integrated additive manufacturing with laser shock peening-induced microstructural evolution and improvement in mechanical 
properties of Ti6Al4V alloy components, Int. J. Mach. Tools Manuf. 148 (2020), 103475, https://doi.org/10.1016/j.ijmachtools.2019.103475.

[15] J. Gale, A. Achuhan, Application of ultrasonic peening during DMLS production of 316L stainless steel and its effect on material behavior, Rapid Prototyp. J. 23 (6) (2017) 1185-1194, https://doi.org/10.1108/RPJ-09-2016-0140.

[16] M. Bambach, I. Sizova, B. Sydow, S. Hemes, F. Meiners, Hybrid manufacturing of components from Ti-6Al-4V by metal forming and wire-arc additive manufacturing, J. Mater. Process. Technol. 282 (2020), 116689, https://doi.org/ 10.1016/j.jmatprotec.2020.116689.

[17] Y. Fu, H. Zhang, G. Wang, H. Wang, Investigation of mechanical properties for hybrid deposition and micro-rolling of bainite steel, J. Mater. Process. Technol. 250 (2017) 220-227, https://doi.org/ 10.1016/j.jmatprotec.2017.07.023.

[18] M. Merklein, D. Junker, A. Schaub, F. Neubauer, Hybrid additive manufacturing technologiesan analysis regarding potentials and applications, Phys. Procedia 83 (2016) 549-559, https://doi .org/10.1016/j.phpro.2016.08.057.

[19] P. Stavropoulos, H. Bikas, O. Avram, A. Valente, G. Chryssolouris, Hybrid subtractive-additive manufacturing processes for high value-added metal components, Int. J. Adv. Manuf. Technol. 111 (2020) 645-655, https://doi.org/10.1007/s00170-020-06099-8.

[20] J.C. Heigel, T.Q. Phan, J.C. Fox, T.H. Gnaupel-Herold, Experimental investigation of residual stress and its impact on machining in hybrid additive/subtractive manufacturing, Procedia Manuf. 26 (2018) 929-940, https://doi.org/10.1016/j.promfg.2018.07.120.

[21] A. Yassin, T. Ueda, A. Hosokawa, T. Furumoto, R. Tanaka, S. Abe, Study on cutting characteristics of sintered material with Yb: fiber laser, J. Adv. Mech. Des. Syst. Manuf. 2 (2008) 833-843, https://doi.org/10.1299/jamdsm.2.833.

[22] V. Tripathi, A. Armstrong, X. Gong, G. Manogharan, T. Simpson, E. De Meter, Milling of Inconel 718 block supports fabricated using laser powder bed fusion, J. Manuf. Process. 34 (2018) 740 749, https://doi.org/10.1016/j. jmapro.2018.03.046.

[23] E. Brinksmeier, R. Gläbe, F. Klocke, D.A. Lucca, Process signatures - an alternative approach to predicting functional workpiece properties, Procedia Eng. 19 (2011) 44-52, https://doi.org/10.1016/ j.proeng.2011.11.078.

[24] E. Brinksmeier, G. Levy, D. Meyer, A.B. Spierings, Surface integrity of selective-laser-melted components, CIRP Ann. 59 (1) (2010) 601-606, https://doi.org/10.1016/j.cirp.2010.03.131.

[25] Y. Ma, P. Feng, J. Zhang, Z. Wu, D. Yu, Energy criteria for machining-induced residual stresses in face milling and their relation with cutting power, Int. J. Adv. Manuf. Technol. 81 (2015) 10231032, https://doi.org/10.1007/s00170-015-7278-9.

[26] D.A. Lesyk, S. Martinez, B.N. Mordyuk, V.V. Dzhemelinskyi, A Lamikiz, G. I. Prokopenko, Postprocessing of the Inconel 718 alloy parts fabricated by selective laser melting: effects of mechanical surface treatments on surface topography, porosity, hardness and residual stress, Surf. Coat. Technol. 381 (2020), 125136, https://doi.org/10.1016/j.surfcoat.2019.125136.

[27] S. Kara, W. Li, Unit process energy consumption models for material removal processes, CIRP Ann. 60 (1) (2011) 37-40, https://doi.org/10.1016/j.cirp.2011.03.018.

[28] J.B. Dahmus, T.G. Gutowski, An environmental analysis of machining, in: Proceedings of the ASME 2004 International Mechanical Engineering Congress and Exposition. Manufacturing Engineering and Materials Handling Engineering. Anaheim, California, USA, 2004, pp. 643-652. https://doi.org/10.1115/IMECE2004-62600. 
[29] Z.Y. Liu, M.P. Sealy, W. Li, D. Zhang, X.Y. Fang, Y.B. Guo, Z.Q. Liu, Energy consumption characteristics in finish hard milling, J. Manuf. Process. 35 (2018) 500-507, https://doi.org/10.1016/ j.jmapro.2018.08.036.

[30] C. Liu, D. Yan, J. Tan, Z. Mai, Z. Cai, Y. Dai, M. Jiang, P. Wang, Z. Liu, C.C. Li, C. Lao, Development and experimental validation of a hybrid selective laser melting and CNC milling system, Addit. Manuf. 36 (2020), 101550, https://doi.org/10.1016/j.addma.2020.101550.

[31] Y. Sun, J. Sun, J. Li, W. Li, B. Feng, Modeling of cutting force under the tool flank wear effect in end milling Ti6Al4V with solid carbide tool, Int. J. Adv. Manuf. Techol. 69 (2013) 2545-2553, https://doi.org/10.1007/s00170-013-5228-y.

[32] Z.Y. Liu, Y.B. Guo, M.P. Sealy, Z.Q. Liu, Energy consumption and process sustainability of hard milling with tool wear progression, J. Mater. Process. Technol. 229 (2016) 305-312. 